\title{
A GRAVITY MAP OF PEARY LAND, NORTH GREENLAND
}

\author{
René Forsberg
}

During the summer of 1978 the Geodetic Institute, Copenhagen, established a regional gravity network as a minor part of the surveying programme, with a combination of barometric, triangulation and doppler-derived heights as vertical control.

A preliminary map of bouguer anomalies with $20 \mathrm{mgal}$ contours is shown in fig. 32 . Terrain-corrected bouguer anomalies will be avilable at a later stage, when the digital terrain models to be used for plotting height curves on the coming ortho-photo maps are completed. It is important to note that the terrain corrections for some stations in very rugged topography might raise the anomalies considerably, up to the order $10 \mathrm{mgal}$.

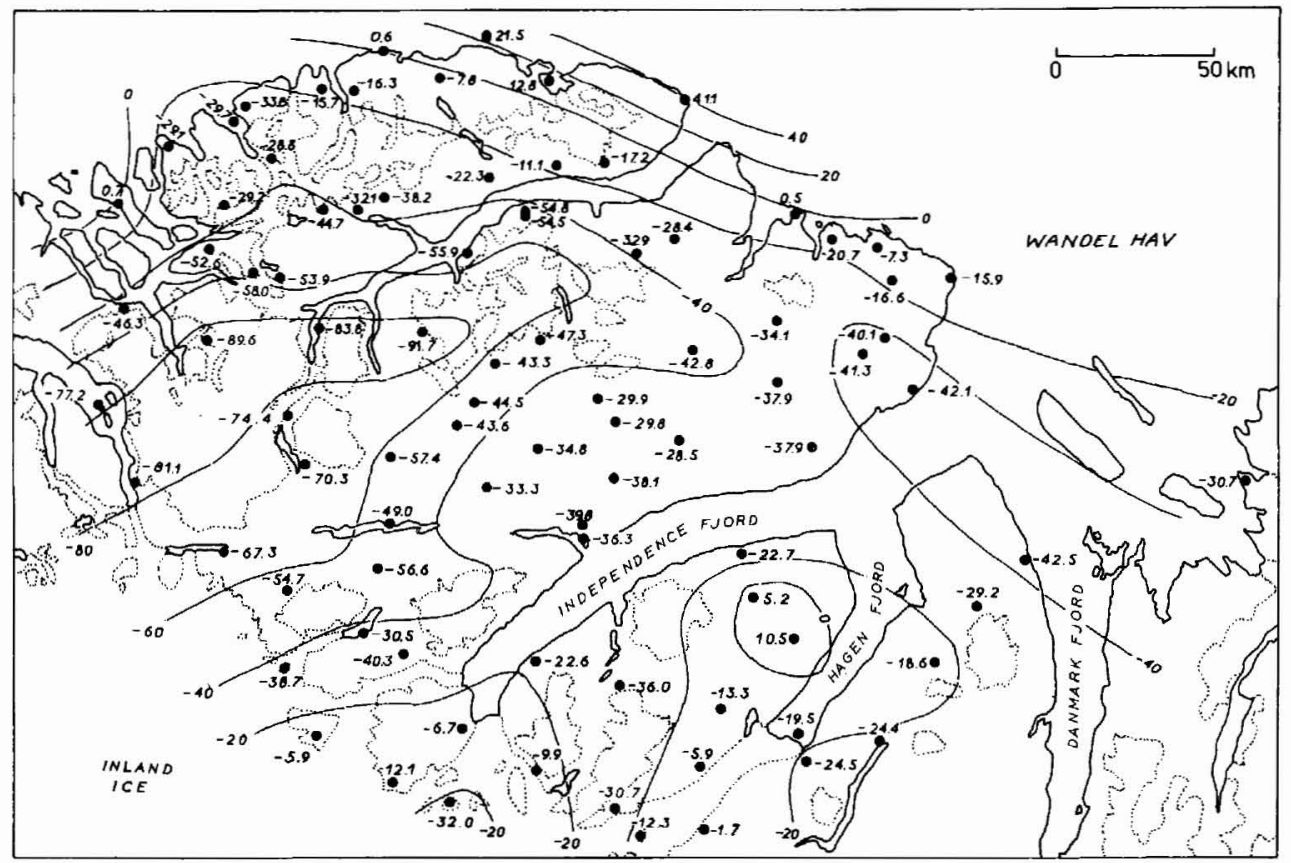

Fig. 32. Bouguer anomaly map of the Peary Land region. Values in mgal. Datum: IGSN 71. Density: $2.67 \mathrm{~g} / \mathrm{cm}^{3}$. No terrain corrections applied. 
The major features of the gravity map are to some extent similar to those observed in the large ice-free areas of West Greenland. Towards the north-east a rapid rise in gravity indicates crustal thinning towards the continental shelf, which is rather narrow in the Wandel Hav. The axis of the deep minimum observed in the Hans Tavsens Iskappe area corresponds fairly well to the deepest part of the Lower Palaeozoic basin, but the main part of the anomaly is probably related to the rise of Greenland, analogous to West Greenland anomalies. To interpret the anomalies it will be necessary to utilize other geophysical data, especially aeromagnetic data, which probably also will show whether the significant positive anomaly to the north-west of Hagen Fjord is related to the Proterozoic dykes and sills in the area.

At present no bulk density information for the most common rocks of the area is available. Any further work with gravity must therefore include a laboratory density determination programme of samples from the major formations. 